\title{
The Facility Management Penetrated to the Life Cycle of the Institutions and Equipments Is the Main Current in
} Future

\author{
Sigeru Nakayama* and Toshiya Kaihara \\ Nakazaki-Nishi, Kita-ku, Osaka 530-0015, Japan \\ *Corresponding author'se-mail: k-ao@hera.eonet.ne.jp
}

\begin{abstract}
In low-growth like these days, people’s consciousness to the environmental consideration is growing, also consumers demand the food-safety and food-confidence. Consumer needs become diversity, though the sales life is shortened. Under such circumstances, it is necessary not only to reduce the construction budget but also to focus on the institution as an operational resource when you construct a new building, reform it or repair it. According to this idea, the most important subject to maintain the company sound is how you activate the operational resource efficiently and effectively by cutting down the LCC. The initial construction cost of ordinary institution is only $1 / 4$ of whole cost from groundbreaking to scrap. In order to reduce the LCC, the company should have the mid-term and long-term prospect, such as 10 years or 20 years terms, and also should improve the institutions and equipments' functions suitably and usefully. Furthermore, those operational resources should be positively renovated to decrease the energy consumption in order to reduce the LCC with the latest technology and within the change in price of energy resources.
\end{abstract}

Key words: People’s consciousness, environmental problems, consumers demand, food-safety, food-confidence. 